\title{
Comparative Analysis on Elastic-plastic Analytical Methods for Tunnel Surrounding Rocks
}

\author{
Chuanqi ZHU, Xingang NIU, Huaifu LIU, Haifeng MA, Zhenhua JIAO
}

\begin{abstract}
Elastic-plastic analysis is an important way to obtain the mechanical characteristics of surrounding rocks. However, selecting a reasonable analytical method is difficult. To explore the differences between the surrounding rocks constitutive relation and yield criterion analytical methods, the stress distribution and deformation characteristics of tunnel surrounding rocks at the $-817 \mathrm{~m}$ firefighting material chamber of the Wangfenggang Well, Xieyi Mine, Huainan Coal Industry Group (China) were analyzed by using the bilinear constitutive relation and unified strength criterion analytical methods. Calculated results of the two analytical methods were compared. The radius and displacement evolution laws of the plastic region on tunnel surrounding rocks with in situ rock stress and supporting resistance were discussed. Results demonstrate that compared with the unified strength criterion analytical method, the bilinear constitutive relation analytical method avoids the influences of intermediate principal stress coefficient on results and the tangential stress distribution curve is smooth. The calculated radius of the plastic region and periphery displacement of the tunnel are $4,365 \mathrm{~m}$ and $87,373 \mathrm{~mm}$, which are higher than those of the unified strength criterion analytical method. Stress difference is a major factor that influences the mechanical characteristics of tunnel surrounding rocks. As the stress difference decreases from 20,4 MPa to $16,4 \mathrm{MPa}$, the radius of the plastic region and periphery displacement of the tunnel decrease by $0,697 \mathrm{~m}$ and $26,73 \mathrm{~mm}$, respectively. This study provides theoretical references for the practical selection of elastic-plastic analytical method for tunnel surrounding rocks.
\end{abstract}

Keywords: bilinear constitutive relation; elastic-plastic analytical method; stress difference; tunnel surrounding rocks; unified strength criterion

\section{INTRODUCTION}

Tunnel is the main passage for coal transportation, mine ventilation, drainage, and human activities. Excavating vast tunnel during the mining of coal resources is necessary. The long-term stability of tunnel is crucial to safe and high-efficiency mining of coal resources. After the tunnel excavation, surrounding rocks experience twodimensional stress instead of the original threedimensional stress. Such stress re-distribution on surrounding rocks causes their deformation and forces them to move toward the tunnel space, thus increasing rock deformation around the tunnel. This condition causes various accidents, such as roof collapse and floor heave, and thereby poses serious threats to safe and highefficiency mining of coal resources. To prevent buckling accidents of tunnel surrounding rocks, many scientific researchers and field technicians have conducted long-term intensive investigations and proposed specific supporting measures for different tunnel surrounding rocks, which ensured the safety and smoothness of tunnel to some extent $[1,2]$.

The accurate acquisition of stress distribution and deformation behaviors of surrounding rocks is the premise to enhancing the stability of surrounding rocks and preventing tunnel accidents. Currently, elastic-plastic analysis is the only way to acquire the mechanical characteristics of surrounding rocks and is the theoretical basis for controlling the stability of surrounding rocks and predicting and preventing rock burst [3-5]. In the elasticplastic analysis of surrounding rocks, the actual mechanical environment in the tunnel is generally simplified and several mechanical parameters that have little influence on the analysis results are often ignored. On this basis, the elastic-plastic analytical method of surrounding rocks is formed based on the different assessment criteria of plastic region on surrounding rocks. Many elastic-plastic analytical methods for tunnel surrounding rocks exist. The illogical selection of elasticplastic analytical method causes significant error between the calculated results and the actual mechanical characteristics of tunnel. Therefore, a suitable elasticplastic analytical method for the stability analysis and support design of tunnel surrounding rocks should be selected according to existing conditions.

\section{STATE OF THE ART}

For the difficult stability control of tunnel surrounding rocks, many theoretical elastic-plastic analyses of the stress distribution and deformation characteristics of surrounding rocks have been performed locally and internationally and provided field technicians solid theoretical basis for tunnel stability evaluation and support design. Fenner and Kastner assumed that tunnel surrounding rocks are ideal elastic-plastic media and determined the elastic-plastic behavior of surrounding rocks according to stress. They believed that surrounding rocks exhibit the plastic behavior when stress satisfies the Mohr-Coulomb strength criterion. Next, they proposed the first elastic-plastic analytical method for round tunnel by combining the equilibrium equation of surrounding rocks. Subsequently, Ranjbarniaetal [6] regarded the constitutive relation of tunnel surrounding rocks as a "straightcurve-straight" model and analyzed the mechanical characteristics of surrounding rocks from the constitutive model selection to obtain an accurate solution. To reproduce real stress behaviors on tunnel surrounding rocks and obtain the stress distribution and displacement behaviors that conform to practical situations, some studies provided appropriate considerations to the influences of intermediate principal stress, determined the elastic-plastic behavior of surrounding rocks according to the yield criteria, such as Hoek-Brown [7, 8], Drucker-Prager [9], and unified strength theory [10], and improved the original elastic-plastic analytical method based on the equilibrium equation of surrounding rocks. These elastic-plastic analytical methods can be summarized as solving based on the yield criteria. The research mentioned formed elastic-plastic analytical methods based on the constitutive model and the yield criteria of surrounding rocks and enriched the theoretical studies on elastic-plastic solutions of tunnel surrounding rocks significantly. However, selecting a specific elastic-plastic analytical method in accordance with the existing conditions of surrounding rocks is difficult due to the diversity and 
unidentified differences of these analytical methods. Other studies determined the elastic-plastic behavior of surrounding rocks according to strain and concluded that surrounding rocks exhibit plastic behavior when the strain exceeds the yield strain. In addition, they deduced the stress state of surrounding rocks in the plastic region according to the stressstrain relation and developed another type of elastic-plastic analytical method based on the constitutive relation of surrounding rocks. The constitutive model based on smooth connection of the elastic, strain nonlinear hardening, and softening stages proposed by Pan et al. [11]is a representative model that analyzed the stress distribution law in the plastic region in a round tunnel. Houet al. [12] studied the elasticplastic behavior of surrounding rocks with strong strain reinforcement effect by the power-hardening constitutive relation. Xiao et al. [13] analyzed the mechanical characteristics of tunnel surrounding rocks on the basis of the common constitutive model in rock engineering. Research on the analytic method based on the constitutive relation of surrounding rocks started later than that based on the yield criteria, and no detailed research on its superiority has been reported. Existing research results do not provide field technicians references for selecting the appropriate elasticplastic analytical method.

To demonstrate accuracy of the elastic-plastic analytical methods for tunnel surrounding rocks, scholars have verified the accuracy of the proposed analytical methods by combining field measurement and numerical calculation. Alejano et al [14] simplified the constitutive model of surrounding rocks into a linear "three-segment" model, proposed an elasticplastic analytical method that conforms to practical situations, and verified the theoretical analysis results through numerical simulation. Guo et al. [15] performed an elastic-plastic analysis on round tunnel under high ground stress based on the unified strength theory and plastic strain damage model considering the intermediate principal stress effect and dilatancy. They verified the validity of the analytical solutions by comparing them with model tests and engineering measurement data. Using the linear softening model, Su et al. [16] illustrated the deformation failure characteristics of surrounding rocks in the mudstone tunnel at the shaft station in Shandong Yuncheng Coal (China) under the expansion and linear softening effects, which were verified through comparison with measurement data and theoretical values. These studies verify the validity of elastic-plastic analytical methods for tunnel surrounding rocks using different research methods. However, field investigation, numerical simulation, and similarity experiments all perform qualitative evaluation on theoretical analysis results due to the significant difference between the actual mechanical state of tunnel and hypothesize mechanical environment of surrounding rocks in theoretical analysis. The solutions can only be evaluated quantitatively and accurately by comparing the results of different theoretical analytical methods. To further study the different elastic-plastic analytical methods for tunnel surrounding rocks and highlight advantages and disadvantages of existing methods comprehensively, a comparative research on the two types of analytic methods should be conducted. Hence, the stress distribution and deformation characteristics of tunnel surrounding rocks are studied according to local geological conditions using the elastic-plastic analytical methods based on the bilinear constitutive relation of surrounding rocks and the unified strength criterion.

The rest of this study is organized as follows. Section 2 introduces the state-of-the-art elastic-plastic analytical methods. Section 3 provides the basic equation that theoretical plans and tunnel surrounding rocks must satisfy. Section 4 discusses and analyzes the theoretical analysis results. Section 5 presents the conclusions.

\section{METHODOLOGY}

\subsection{Geological Conditions of Tunnel Surrounding Rocks}

A firefighting material chamber exists at $-817 \mathrm{~m}$ deep of the Wangfenggang Well, Xieyi Mine, Huainan Coal Industry Group (China). It is $5940 \mathrm{~mm}$ wide and $4700 \mathrm{~mm}$ high tunnel with a straight wall and a semi-circular arch. This arc tunnel could be changed into a round tunnel by using the radius $r_{0}$ as the characteristic size in the following formula [17]:

$r_{0}=k(S / \pi)^{1 / 2}$

where $S$ is the actual sectional area of the tunnel, and $k$ is the section shape correction coefficient, which is 1,1 for the arc tunnel. Therefore, $r_{0}=3,66 \mathrm{~m}$ according to Eq. (1). The in situ rock stress where the tunnel surrounding rocks are situated and the supporting resistance of the surrounding rocks were assumed 22,4 and $1 \mathrm{MPa}$, respectively. The peak strain, elastic modulus, softening modulus, tensioncompression strength ratio, and dilatation coefficient of the surrounding rocks are 0,$02 ; 1,5 \mathrm{GPa} ; 3 \mathrm{GPa} ; 0,34$, and 1,1 , respectively.

\subsection{Bilinear Constitutive Relation of Rocks}

The bilinear constitutive relation of rocks ignores the pre-peak damage of rocks and predicts linear damage softening after the peak. The one-dimensional damage evolution equation of rocks is defined as:

$D=\left\{\begin{array}{cc}0 & \left(\varepsilon<\varepsilon_{\mathrm{c}}\right) \\ \frac{\lambda}{E}\left(\frac{\varepsilon}{\varepsilon_{\mathrm{c}}}-1\right) & \left(\varepsilon \geq \varepsilon_{\mathrm{c}}\right)\end{array}\right.$

where $\lambda$ is the softening modulus during the softening stage, $E$ is the elastic modulus, $\varepsilon$ is the strain under the uniaxial compression of rocks, and $\varepsilon_{\mathrm{c}}$ is the peak strain. The constitutive relation of rocks under uniaxial compression can be expressed as:

$$
\sigma=\left\{\begin{array}{cl}
E \varepsilon & \left(\varepsilon<\varepsilon_{\mathrm{c}}\right) \\
E \varepsilon\left[1-\frac{\lambda}{E}\left(\frac{\varepsilon}{\varepsilon_{\mathrm{c}}}-1\right)\right] & \left(\varepsilon \geq \varepsilon_{\mathrm{c}}\right)
\end{array}\right.
$$


The stress-strain relation curve of rocks under uniaxial compression is shown in Fig. 1, where $\sigma_{\mathrm{c}}$ is the peak stress. The curve can be generally simplified into two stages: linear elasticity stage (OA) and linear damage softening stage (AB).

\subsection{Unified Strength Criterion}

The unified strength criterion considers the effect of intermediate principle stress and is widely used in the elastic-plastic analysis of tunnel surrounding rocks. If the compressive stress is positive and the tensile stress is negative, the expression of principle stress in the unified strength criterion is as follows [18]:

$$
\left\{\begin{array}{cc}
F=a \sigma_{1}-\frac{b \sigma_{2}+\sigma_{3}}{1+b}=a \sigma_{c} & \sigma_{2} \leq \frac{a \sigma_{1}+\sigma_{3}}{1+a} \\
F=\frac{a}{1+b}\left(\sigma_{1}+b \sigma_{2}\right)-\sigma_{3}=a \sigma_{c} & \sigma_{2} \geq \frac{a \sigma_{1}+\sigma_{3}}{1+a}
\end{array}\right.
$$

where $\sigma_{1}, \sigma_{2}$ and $\sigma_{3}$ are the maximum, intermediate, minimum principal stresses on the tunnel surrounding rocks respectively; $a$ is the ratio between the uniaxial tensile strength and the uniaxial compressive strength of surrounding rocks, it is tensile / compressive strength ratio; and $b$ is the influence degree of intermediate principal shear stress and normal positive stress on the intermediate principal shear stress acting surface on the surrounding rocks failure, that is, $0 \leq b \leq 1$. The higher $b$ is, the stronger the intermediate principal stress will be.

\subsection{Mechanical Model of Round tunnel Surrounding Rocks}

Stress is redistributed on the surrounding rocks after tunnel excavation. The surrounding rocks close to the tunnel could be divided into the plastic, elastic, and in situ rock stress regions. This mechanical model hypothesizes that tunnel surrounding rocks are homogeneous, macroscopically isotropic, and distributed in the situ stress field uniformly. Meanwhile, the dead weight of surrounding rocks is ignored. The mechanical model is shown in Fig. 2, where $p_{0}$ is the in situ rock stress, $r_{\mathrm{s}}$ is the radius of the plastic region, and $p_{\mathrm{s}}$ is the supporting resistance.

The mechanical model of a tunnel is a symmetric plane bearing. The stress and strain on tunnel surrounding rocks is expressed as:

$\left\{\begin{array}{l}\varepsilon_{\mathrm{z}}=\frac{1}{E}\left[\sigma_{\mathrm{z}}-v\left(\sigma_{\theta}+\sigma_{\mathrm{r}}\right)\right] \\ \varepsilon_{\mathrm{z}}=0\end{array}\right.$

where $v$ is the Poisson's ratio of the surrounding rocks; $\sigma_{\theta}$, $\sigma_{\mathrm{r}}$ and $\sigma_{\mathrm{z}}$ are the tangential, radial, and axial stresses of the surrounding rocks; and $\varepsilon_{\mathrm{z}}$ is the axial strain of the surrounding rocks. Under hydrostatic pressure, $v=0,5$. By combining with Eq. (5), an expression on $\sigma_{\theta}$ and $\sigma_{\mathrm{r}}$ is obtained as follows:

$\sigma_{\mathrm{z}}=0,5\left(\sigma_{\theta}+\sigma_{\mathrm{r}}\right)$

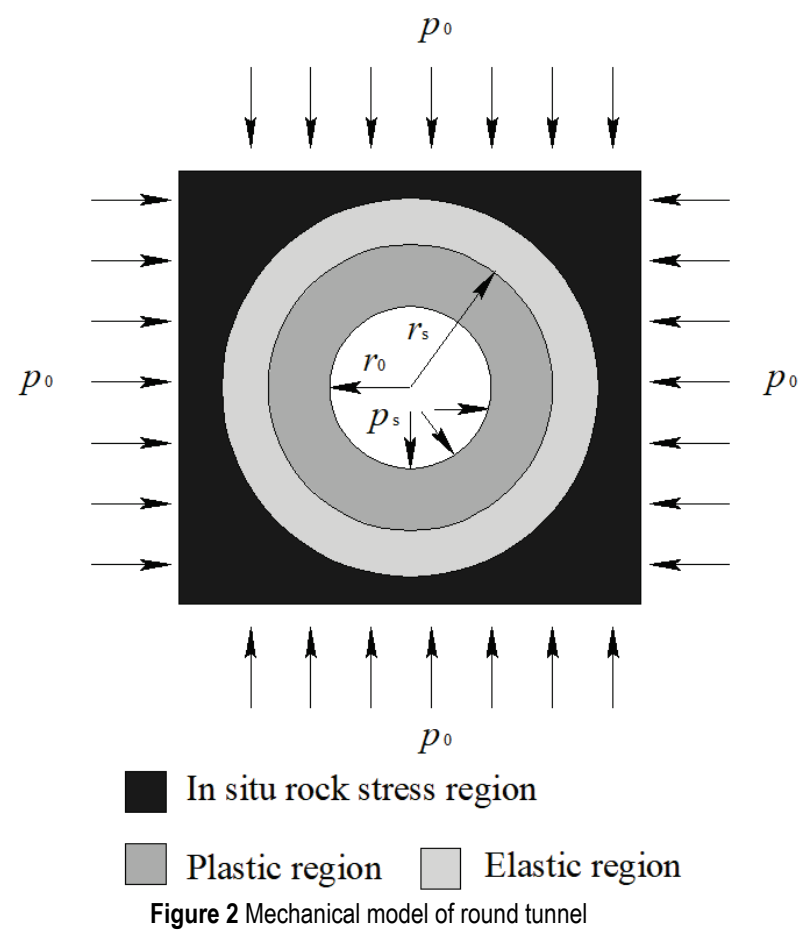

Surrounding rocks significantly suffer volume expansion during the plastic softening stage, which apparently shows the dilatancy phenomenon. Surrounding rocks satisfy:

$\varepsilon_{\mathrm{r}}+\eta \varepsilon_{\theta}=0$

where $\varepsilon_{\theta}$ and $\varepsilon_{\mathrm{r}}$ are the tangential and radial strains of tunnel surrounding rocks, and $\eta$ is the dilatancy coefficient. $\varepsilon_{\theta}$ and $\varepsilon_{\mathrm{r}}$ satisfy the following geometric equations:

$\varepsilon_{\theta}=\frac{u}{r}$

$\varepsilon_{\mathrm{r}}=\frac{\mathrm{d} u}{\mathrm{~d} r}$

where $u$ is the radial displacement of surrounding rocks, and $r$ is the distance from the surrounding rocks to the tunnel center. $\sigma_{\theta}$ and $\sigma_{\mathrm{r}}$ satisfy the equilibrium differential equation:

$\frac{\mathrm{d} \sigma_{\mathrm{r}}}{\mathrm{d} r}+\frac{\sigma_{\mathrm{r}}-\sigma_{\theta}}{r}=0$

By combining Eq. (7) and Eq. (8), an expression about $u$ and $r$ is obtained. $u$ and $r$ satisfy:

$\frac{\mathrm{d} u}{\mathrm{~d} r}+\eta \frac{u}{r}=0$

The expression of the surrounding rocks displacement $(u)$ is obtained by integrating Eq. (10). $u$ satisfies:

$u=\frac{C_{1}}{r^{\eta}}$

where $C_{1}$ is an integral constant. 
Tangential strain $\varepsilon_{\theta}$ and radial strain $\varepsilon_{\mathrm{r}}$ are deduced from Eq. (11) and Eq. (8). They satisfy:

$$
\begin{aligned}
& \varepsilon_{\theta}=\frac{C_{1}}{r^{\eta+1}} \\
& \varepsilon_{\mathrm{r}}=-\frac{\eta C_{1}}{r^{\eta+1}}
\end{aligned}
$$

The strain of the surrounding rocks in the plastic region is higher than the peak strain, and the surrounding rocks in the plastic region correspond to the damage softening stage in the stress-strain curve of rocks. Eq. (12) shows that the strain of the surrounding rocks increases proportionally. According to the total strain theory [19], the constitutive relation of the surrounding rocks in the plastic region under complex stress is determined according to Eq. (3). Its expression is:

$\sigma_{\mathrm{i}}=E \varepsilon_{\mathrm{i}}\left[1-\frac{\lambda}{E}\left(\frac{\varepsilon_{\mathrm{i}}}{\varepsilon_{\mathrm{c}}}-1\right)\right] \quad\left(\varepsilon_{\mathrm{i}} \geq \varepsilon_{\mathrm{c}}\right)$

where $\sigma_{\mathrm{i}}$ is the equivalent stress, and $\varepsilon_{\mathrm{i}}$ is the equivalent strain. $\sigma_{\mathrm{i}}$ and $\varepsilon_{\mathrm{i}}$ are expressed as:

$$
\begin{aligned}
& \sigma_{\mathrm{i}}=\frac{\sqrt{2}}{2} \sqrt{\left(\sigma_{\theta}-\sigma_{\mathrm{r}}\right)^{2}+\left(\sigma_{\mathrm{r}}-\sigma_{\mathrm{z}}\right)^{2}+\left(\sigma_{\mathrm{z}}-\sigma_{\theta}\right)^{2}} \\
& \varepsilon_{\mathrm{i}}=\frac{\sqrt{2}}{3} \sqrt{\left(\varepsilon_{\theta}-\varepsilon_{\mathrm{r}}\right)^{2}+\left(\varepsilon_{\mathrm{r}}-\varepsilon_{\mathrm{z}}\right)^{2}+\left(\varepsilon_{\mathrm{z}}-\varepsilon_{\theta}\right)^{2}}
\end{aligned}
$$

The damage variable of surrounding rocks in the plastic region $\left(D_{\mathrm{t}}\right)$ under complex stress satisfies:

$D_{\mathrm{t}}=\frac{\lambda}{E}\left(\frac{\varepsilon_{\mathrm{i}}}{\varepsilon_{\mathrm{c}}}-1\right) \quad\left(\varepsilon_{\mathrm{i}} \geq \varepsilon_{\mathrm{c}}\right)$

Eq. (12) is substituted into the second Eq. (14). The expression on $\varepsilon_{\mathrm{i}}$ is obtained by combining the second Eq. (5) $\varepsilon_{\mathrm{i}}$ satisfies:

$\varepsilon_{\mathrm{i}}=\frac{2 C_{1} \sqrt{\eta^{2}+\eta+1}}{3 r^{\eta+1}}$

$\varepsilon_{\mathrm{i}}=\varepsilon_{\mathrm{c}}$ is satisfied when $r=r_{\mathrm{s}} . C_{1}$ is expressed as follows:

$$
C_{1}=\frac{3 \varepsilon_{\mathrm{c}} r_{\mathrm{s}}^{\eta+1}}{2 \sqrt{\eta^{2}+\eta+1}}
$$

Displacement $(u)$, tangential strain $\left(\varepsilon_{\theta}\right)$, radial strain $\left(\varepsilon_{\mathrm{r}}\right)$, and equivalent strain $\left(\varepsilon_{\mathrm{i}}\right)$ of the surrounding rocks are calculated from Eq. (11), Eq. (12), Eq. (16), and Eq. (17), respectively. $u, \varepsilon_{\theta}, \varepsilon_{\mathrm{r}}$ and $\varepsilon_{\mathrm{i}}$ are expressed as follows:

$$
u=\frac{3 \varepsilon_{\mathrm{c}} r_{\mathrm{s}}^{\eta+1}}{2 r^{\eta} \sqrt{\eta^{2}+\eta+1}}
$$

$$
\left.\begin{array}{l}
\varepsilon_{\theta}=\frac{3 \varepsilon_{\mathrm{c}} r_{\mathrm{s}}^{\eta+1}}{2 r^{\eta+1} \sqrt{\eta^{2}+\eta+1}} \\
\varepsilon_{\mathrm{r}}=\frac{3 \varepsilon_{\mathrm{c}_{\mathrm{s}}} \eta^{\eta+1} \eta}{2 r^{\eta+1} \sqrt{\eta^{2}+\eta+1}} \\
\varepsilon_{\mathrm{i}}=\varepsilon_{\mathrm{c}} \frac{r_{\mathrm{s}}^{\eta+1}}{r^{\eta+1}}
\end{array}\right\}
$$

The elastic-plastic analysis based on the constitutive relation of surrounding rocks was performed first. The elastic-plastic behavior of surrounding rocks according to strain was determined by using the bilinear constitutive relation of surrounding rocks and the mechanical model of round tunnel as the theoretical basis. The surrounding rocks exhibit plastic behavior when strain exceeds the yield strain. Subsequently, the radius of the plastic region of the surrounding rocks was determined by combining the stress-strain relation and the equilibrium equation of surrounding rocks. On this basis, the expressions of stress, displacement, and other parameters of surrounding rocks were deduced. Second, the elastic-plastic analysis of surrounding rocks based on the yield criteria was conducted. The elastic-plastic behavior of surrounding rocks according to stress was determined by using the unified strength theory and the mechanical model of round tunnel as the theoretical basis. The surrounding rocks exhibit plastic behavior when stress satisfies the theoretical expression of unified strength. Subsequently, the radius of the plastic region of surrounding rocks was determined by combining the equilibrium equation. On this basis, the expressions of stress, displacement, and other parameters of surrounding rocks were deduced. Finally, the analysis results based on the constitutive relation of the surrounding rocks and the yield criteria were compared through examples. The radius and displacement evolution laws of the plastic region with in situ rock stress and supporting resistance were discussed using the analytical method based on the bilinear constitutive relation.

\section{RESULT ANALYSIS AND AISCUSSION \\ 4.1 Analysis Results Based on the Bilinear Constitutive Relation \\ 4.1.1 Stress in the Elastic Region}

$\sigma_{\mathrm{s}}$ was assumed as the radial stress at the elastic-plastic junction of the surrounding rocks and $\sigma_{\mathrm{s}}$ was used as the supporting resistance of the elastic region against the surrounding rocks. Then, the stresses in the elastic region of surrounding rocks are expressed as:

$$
\left.\begin{array}{l}
\sigma_{\mathrm{r}}=\sigma_{\mathrm{s}} \frac{r_{\mathrm{s}}^{2}}{r^{2}}+p_{0}\left(1-\frac{r_{\mathrm{s}}^{2}}{r^{2}}\right) \\
\sigma_{\theta}=-\sigma_{\mathrm{s}} \frac{r_{\mathrm{s}}^{2}}{r^{2}}+p_{0}\left(1+\frac{r_{\mathrm{s}}^{2}}{r^{2}}\right)
\end{array}\right\}
$$

\subsubsection{Stress in the Plastic Region}

The radial stress in the plastic region of surrounding rocks $\left(\sigma_{\mathrm{r}}\right)$ is expressed as follows: 


$$
\begin{aligned}
& \sigma_{\mathrm{r}}=\frac{\sqrt{3} \lambda \varepsilon_{\mathrm{c}}}{3(\eta+1)}\left(\frac{r_{\mathrm{s}}^{2 \eta+2}}{r^{2 \eta+2}}-\frac{r_{\mathrm{s}}^{2 \eta+2}}{r_{0}^{2 \eta+2}}\right)+p_{\mathrm{s}}- \\
& -\frac{2 \sqrt{3} E \varepsilon_{\mathrm{c}}}{3(\eta+1)}\left(\frac{\lambda}{E}+1\right)\left(\frac{r_{\mathrm{s}}^{\eta+1}}{r^{\eta+1}}-\frac{r_{\mathrm{s}}^{\eta+1}}{r_{0}^{\eta+1}}\right)
\end{aligned}
$$

The tangential stress in the plastic region of the surrounding rocks $\left(\sigma_{\theta}\right)$ is expressed as follows:

$$
\begin{aligned}
& \sigma_{\theta}=\frac{\sqrt{3} \lambda \varepsilon_{\mathrm{c}}}{3(\eta+1)}\left(\frac{r_{\mathrm{s}}^{2 \eta+2}}{r^{2 \eta+2}}-\frac{r_{\mathrm{s}}^{2 \eta+2}}{r_{0}^{2 \eta+2}}\right)+p_{\mathrm{s}}- \\
& -\frac{2 \sqrt{3} E \varepsilon_{\mathrm{c}}}{3(\eta+1)}\left(\frac{\lambda}{E}+1\right)\left(\frac{r_{\mathrm{s}}^{\eta+1}}{r^{\eta+1}}-\frac{r_{\mathrm{s}}^{\eta+1}}{r_{0}^{\eta+1}}\right)+ \\
& +\frac{2 \sqrt{3} E \varepsilon_{\mathrm{c}} r_{\mathrm{s}}^{\eta+1}}{3 r^{\eta+1}}\left[1-\frac{\lambda}{E}\left(\frac{r_{\mathrm{s}}^{\eta+1}}{r^{\eta+1}}-1\right)\right]
\end{aligned}
$$

\subsubsection{Radius and Displacement in the Plastic Region}

The expression of radius in the plastic region $r_{\mathrm{s}}$ is:

$r_{\mathrm{s}}=\left[\frac{r_{0}^{\eta+1}\left(-B \pm \sqrt{B^{2}-4 A C}\right)}{2 A}\right]^{\frac{1}{\eta+1}}$

where $\quad A=\lambda \varepsilon_{\mathrm{c}}, \quad B=-2(\lambda+E) \varepsilon_{\mathrm{c}} \quad$ and $C=\sqrt{3}(\eta+1)\left(p_{0}-p_{\mathrm{s}}\right)+2 \varepsilon_{\mathrm{c}}(\lambda+E)-\varepsilon_{\mathrm{c}}[E(\eta+1)+\lambda]$.

The displacement of the tunnel surrounding rocks $(u)$ satisfies:

$u=\frac{3 \varepsilon_{\mathrm{c}} r_{0}^{\eta+1}-\left(B \pm \sqrt{B^{2}-4 A C}\right)}{4 A r^{\eta} \sqrt{\eta^{2}+\eta+1}}$

The periphery displacement of the tunnel $\left(\mu_{0}\right)$ is

$$
u_{0}=\frac{3 \varepsilon_{\mathrm{c}} r_{0}\left(-B \pm \sqrt{B^{2}-4 A C}\right)}{4 A \sqrt{\eta^{2}+\eta+1}}
$$

\subsection{Analysis Results Based on the Unified Strength Criterion}

\subsubsection{Stress in the Elastic Region}

The calculated stress in the elastic region of the surrounding rocks based on the unified strength criterion is consistent with that based on the bilinear constitutive relation. The stress expression in the elastic region is the same as Eq. (21).

\subsubsection{Stress in the Plastic Region}

The radial stress $\left(\sigma_{\mathrm{r}}\right)$ and tangential stress $\left(\sigma_{\theta}\right)$ at the elastic-plastic junction of the surrounding rocks $\left(r=r_{\mathrm{s}}\right)$ satisfy:

$\sigma_{\theta}+\sigma_{\mathrm{r}}=2 p_{0}$

The radial stress in the plastic region of the surrounding rocks $\left(\sigma_{\mathrm{r}}\right)$ is:

$\sigma_{\mathrm{r}}=\frac{B_{1} E+\lambda B_{1}}{\left(1-A_{1}\right) E}+\frac{\lambda B_{1} r_{\mathrm{s}}^{\eta+1}}{E\left(A_{1}+\eta\right) r^{\eta+1}}+$

$+\frac{r^{A-1}}{r_{0}^{A-1}}\left[p_{\mathrm{s}}-\frac{B_{1} E+\lambda B_{1}}{\left(1-A_{1}\right) E}-\frac{\lambda B_{1} r_{\mathrm{s}}^{\eta+1}}{E\left(A_{1}+\eta\right) r_{0}^{\eta+1}}\right]$

where $A_{1}=\frac{2+2 b-a b}{a(2+b)}$ and $B_{1}=\frac{2(1+b)}{2+b} \sigma_{\mathrm{c}}$.

The tangential stress in the plastic region of the surrounding rocks $\left(\sigma_{\theta}\right)$ is

$$
\begin{aligned}
& \sigma_{\theta}=\frac{A_{1} B_{1}(E+\lambda)}{\left(1-A_{1}\right) E}+\frac{A_{1} \lambda B_{1} r_{\mathrm{s}}^{\eta+1}}{E\left(A_{1}+\eta\right) r^{\eta+1}}+\left[1-\frac{\lambda}{E}\left(\frac{r_{\mathrm{s}}^{\eta+1}}{r^{\eta+1}}-1\right)\right] B_{1} . \\
& \frac{A_{1} r^{A-1}}{r_{0}^{A-1}}\left[p_{\mathrm{s}}-\frac{B_{1} E+\lambda B_{1}}{\left(1-A_{1}\right) E}-\frac{\lambda B_{1} r_{\mathrm{s}}^{\eta+1}}{E\left(A_{1}+\eta\right) r_{0}^{\eta+1}}\right]
\end{aligned}
$$

\subsubsection{Radius and Displacement of the Plastic Region}

The radius of the plastic region $\left(r_{\mathrm{s}}\right)$ is calculated by combining Eq. (27), Eq. (28) and Eq. (29). Then, the periphery displacement of the tunnel $\left(\mu_{0}\right)$ is calculated.

Elastic-plastic analytical methods based on the constitutive relation of surrounding rocks and the yield criteria are developed from the existing elastic-plastic analytical methods for tunnel surrounding rocks. They reflect the elastic-plastic analysis concept of surrounding rocks and are applicable to many fields. According to the analytic expressions of surrounding rocks, the expression based on the unified strength criterion has an additional parameter $b$ in addition to the basic parameters of surrounding rocks, such as $r_{0}, p_{0}, p_{\mathrm{s}}, \varepsilon_{\mathrm{c}}, E, \lambda, a$, and $\eta$. The basic mechanical parameters of surrounding rocks, except for $b$, are obtained accurately through field or indoor test, whereas $b$ cannot be determined accurately and reflects the influence degree of intermediate principle stress. The final analysis results are influenced by $b$ significantly. Therefore, the analysis results should be discussed based on the unified strength criterion under different $b$ values.

\subsection{Comparison of Analysis Results between the Bilinear Constitutive Relation and Unified Strength Criterion}

The analysis results based on the constitutive relation of surrounding rocks and the yield criteria are listed in Tab. 1. The stress distribution and displacement distribution curves of surrounding rocks are shown in Fig. 3 and Fig. 4. As shown in Tab. 1 and Fig. 3 and Fig. 4, intermediate principal coefficient $b$ significantly influences the analysis results based on the unified strength criterion. $r_{\mathrm{s}}$ and $\mu_{0}$ decrease to different degrees with the increase of $b$. The tangential stress peak $\sigma_{\theta \max }$ increases gradually, the peak 
position moves toward the tunnel wall, and the radial stress remains basically the same. When $b$ increases from 0 to 1 , $r_{\mathrm{s}}$ decreases by $0,380 \mathrm{~m}$ from $4,044 \mathrm{~m}$ to $3,664 \mathrm{~m}$. $u_{0}$ decreases by $18,75 \%$ from $74,430 \mathrm{~mm}$ to $60,478 \mathrm{~mm}$, and $\sigma_{\theta \max }$ increases by $2,707 \mathrm{MPa}$.

Table 1 Analysis results based on the constitutive relation and yield criteria of surrounding rocks

\begin{tabular}{|c|c|c|c|c|}
\hline \multicolumn{2}{|c|}{ Elastic-plastic analytical methods } & $\begin{array}{l}\text { The radius of the plastic } \\
\text { region } r_{\mathrm{s}} / \mathrm{m}\end{array}$ & $\begin{array}{l}\text { The periphery displacement of the } \\
\text { tunnel } \mu_{0} / \mathrm{mm}\end{array}$ & $\begin{array}{c}\text { The tangential stress peak } \\
\sigma_{\theta \max } / \mathrm{MPa}\end{array}$ \\
\hline \multirow{6}{*}{$\begin{array}{l}\text { Based on the } \\
\text { unified } \\
\text { strength } \\
\text { criterion }\end{array}$} & $b=0$ & 4,044 & 74,430 & 41,050 \\
\hline & $b=0,2$ & 3,883 & 68,342 & 41,875 \\
\hline & $b=0,4$ & 3,795 & 65,136 & 42,494 \\
\hline & $b=0,6$ & 3,737 & 63,044 & 42,998 \\
\hline & $b=0,8$ & 3,697 & 61,626 & 43,394 \\
\hline & $b=1$ & 3,664 & 60,478 & 43,757 \\
\hline \multicolumn{2}{|c|}{ Based on the bilinear constitutive relation } & 4,365 & 87,373 & 39,721 \\
\hline
\end{tabular}

Higher $r_{s}(4,365 \mathrm{~m})$ and $\mu_{0}(87,373 \mathrm{~mm})$ were obtained than those using the analytic method based on the unified strength criterion and the bilinear constitutive relation analytical method avoids the influences of $b$ on the elasticplastic analysis results of surrounding rocks. Assessing the stability of surrounding rocks by using the bilinear constitutive relation is safer for field technicians. For the bilinear constitutive relation analytical method, the tangential stress peak $\sigma_{\theta \max }$ is small $(39,721 \mathrm{MPa})$ and the tangential stress distribution curve is smooth, which indicate the gentle fluctuation with $r$. The stress distribution characteristics of surrounding rocks calculated using the analytical method based on the bilinear constitutive relation are consistent with practical situations.

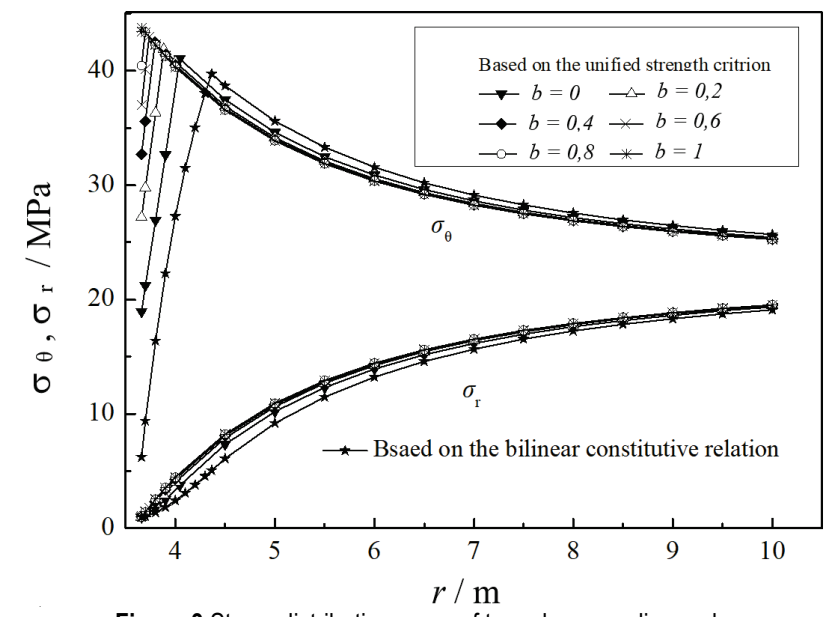

Figure 3 Stress distribution curve of tunnel surrounding rocks

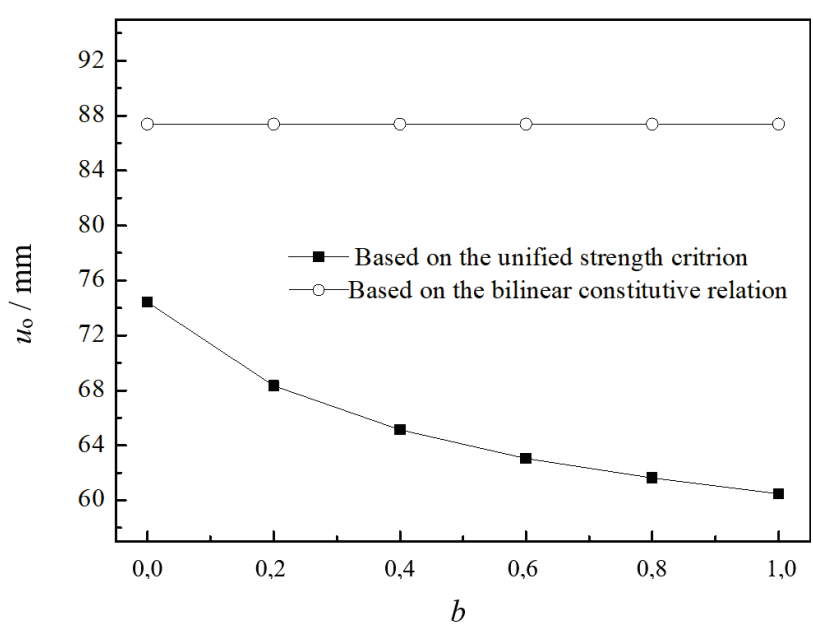

Figure 4 Periphery displacement distribution curve of the tunnel

The radial stresses of surrounding rocks calculated by the two analytical methods are similar.

The differences between the bilinear constitutive relation of rocks and the unified strength criterion analytical methods were studied based on specific geological conditions at the $-817 \mathrm{~m}$ firefighting material chamber of the Wangfenggang Well, Xieyi Mine, Huainan Coal Industry Group (China). Although the conclusions are not universal, the analytical method based on the constitutive relation of surrounding rocks can avoid the influences of intermediate principal stress coefficient $(b)$ and other related factors effectively. When calculating tunnel under specific geological and mining conditions, field technicians should select the practical constitutive model and yield criteria of surrounding rocks, use the two types of analytic methods comprehensively, evaluate the mechanical state of surrounding rocks practically, and ensure the stability of the tunnel surrounding rocks.

\subsection{Effects of Stress Difference on the Range of the Plastic Region and Periphery Displacement of the Tunnel}

After tunnel excavation, the surrounding rocks produce a plastic region and displacements due to in situ rock stress and supporting resistance. The effects on the range of the plastic region are shown in Fig. 5, and the effects of in situ rock stress and supporting resistance on periphery displacement of the tunnel are shown in Fig. 6.

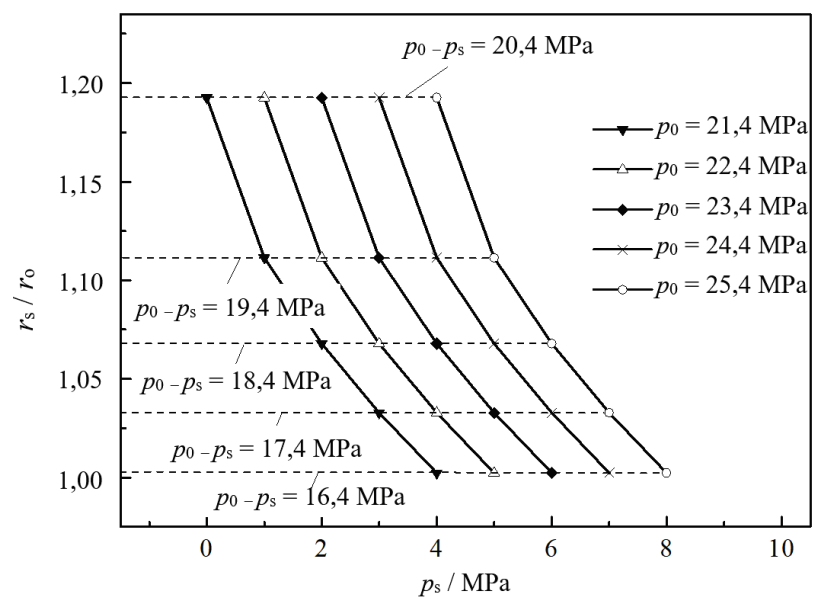

Figure 5 Effects of in situ rock stress and supporting resistance on the range of the plastic region

With the decrease of $p_{0}$ or increase of $p_{\mathrm{s}}, r_{\mathrm{s}} / r_{0}$ and $\mu_{0}$ decrease significantly. However, $r_{\mathrm{s}} / r_{0}$ and $\mu_{0}$ remain constant when $\left(p_{0}-p_{\mathrm{s}}\right)$ is fixed. Eq. (24) and Eq. (26) show that $r_{\mathrm{s}} / r_{0}$ and $u_{0}$ change with $\left(p_{0}-p_{\mathrm{s}}\right)$ rather than single $p_{0}$ 
or $p_{\mathrm{s}},\left(p_{0}-p_{\mathrm{s}}\right)$ is the stress difference. When $\left(p_{0}-p_{\mathrm{s}}\right)$ is small, $r_{\mathrm{s}} / r_{0}$ and $u_{0}$ are low and the surrounding rocks have high stability. When $\left(p_{0}-p_{\mathrm{s}}\right)$ is large, $r_{\mathrm{s}} / r_{0}$ and $\mu_{0}$ are high and the surrounding rocks have low stability. The plastic region range and periphery displacement of the tunnel are positively correlated with stress difference. When $\left(p_{0}-p_{\mathrm{s}}\right)$ decreases from $20,4 \mathrm{MPa}$ to $16,4 \mathrm{MPa}, r_{\mathrm{s}}$ and $\mu_{0}$ decrease by $0,697 \mathrm{~m}$ and $26,73 \mathrm{~mm}$, respectively.

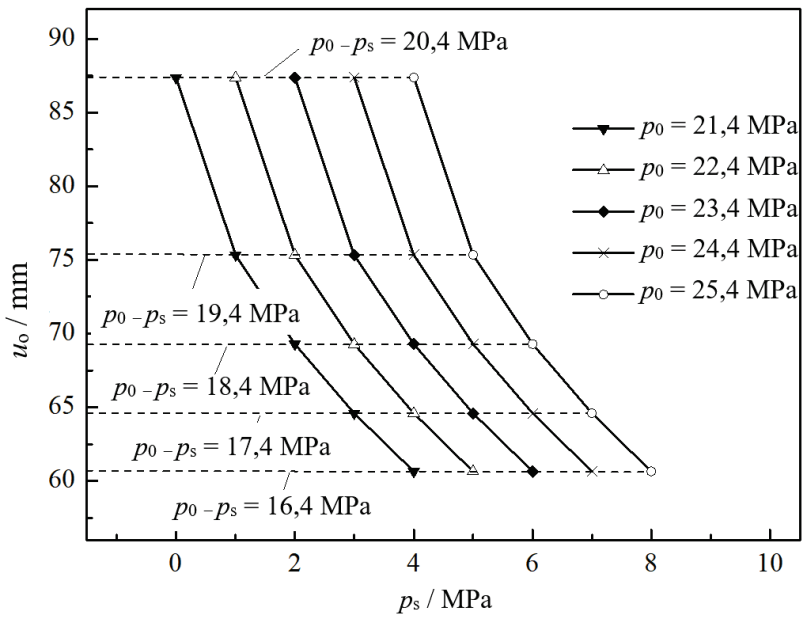

Figure 6 Effects of in situ rock stress and supporting resistance on periphery displacement of the tunnel

By placing the tunnel in the region with small in situ rock stress and enhancing the supporting resistance, the goals of reducing stress difference, narrowing the range of the plastic region, controlling the displacement of surrounding rocks, and increasing the stability of surrounding rocks can be achieved.

\section{CONCLUSIONS}

Selecting a suitable elastic-plastic analysis for tunnel surrounding rocks is difficult. To show the differences among existing analytical methods comprehensively, the analysis results based on the constitutive relation of surrounding rocks and the yield criteria were compared. The mechanical characteristics variation law of tunnel surrounding rocks was discussed by using the analytical method based on the constitutive relation of surrounding rocks. The major conclusions of this study are as follows:

(1) The analytical method based on the bilinear constitutive relation avoids the influences of intermediate principal stress coefficient on calculated results. The calculated radius of the plastic region and periphery displacement of the tunnel are 4,365 $\mathrm{m}$ and $87,373 \mathrm{~mm}$, which are larger than those calculated by the analytical method based on the unified strength criterion. The bilinear constitutive relation analytical method provides a safer assessment of the stability of surrounding rocks, lower tangential stress peak of surrounding rocks, smoother distribution curve of tangential stress, and higher conformity of stress distribution on surrounding rocks with practical distribution pattern than the unified strength criterion analytical method.

(2) Stress difference is the fundamental influencing factor on the mechanical characteristics of surrounding rocks. The range of the plastic region and periphery displacement of the tunnel are positively correlated with stress difference. As the stress difference decreases from $20,4 \mathrm{MPa}$ to $16,4 \mathrm{MPa}$, the radius of the plastic region of surrounding rocks decreases by $0,697 \mathrm{~m}$ and the periphery displacement of the tunnel decreases by $26,73 \mathrm{~mm}$. Low stress difference is conducive to the stability of surrounding rocks.

The advantages and disadvantages of elastic-plastic analytical methods based on the constitutive relation of surrounding rocks and the yield criteria were compared. Research conclusions provide the theoretical basis for field technicians to select the suitable elastic-plastic analytical method. The results of bilinear constitutive relationship and unified strength criterion analytical methods are analyzed to overcome mathematical difficulties and obtain corresponding solutions. Future comparative study between the analysis results of the two methods and other analytical methods is required.

\section{Acknowledgements}

This study was supported by the foundation of educational commission of Anhui province (KJ2019A0130); National Natural Science Foundation (51904010); Anhui Provincial Natural Science Foundation (1808085QE149, 1908085QE184).

\section{REFERENCES}

[1] Ma, N. J., Li, J., \& Zhao, Z. Q. (2015). Distribution of the deviatoric stress field and plastic zone in circular roadway surrounding rock. Journal of China University of Mining \& Technology, 44(2), 206-213

https://doi.org/10.13247/j.cnki.jcumt.000309

[2] Cantieni, L. \& Anagnostou, G. (2011). On a paradox of elasto-plastic tunnel analysis. Rock Mechanics and Rock Engineering, 44(2), 129-147. https://doi.org/10.1007/s00603-010-0126-1

[3] Shahrour, I., Khoshnoudian, F., Sadek, M. \& Mroueh, H. (2010). Elastoplastic analysis of the seismic response of tunnels in soft soils. Tunnelling and Underground Space Technology, 25(4), 478-482. https://doi.org/10.1016/j.tust.2010.01.006

[4] Maleki, M. \& Mousivand, M. (2014). Safety evaluation of shallow tunnel based on elastoplastic-viscoplastic analysis. ScientiaIranica, 21(5), 1480-1491.

[5] Jiang, F. X., Feng, Y., Kouame, K. J. A. \& Wang, J. C. (2015). Mechanism of creep-induced rock burst in extrathick coal seam under high ground stress. Chinese Journal of Geotechnical Engineering, 37(10), 1762- 1768. https://doi.org/10.11779/CJGE201510003

[6] Ranjbarnia, M., Fahimifar, A. \& Oreste, P. (2015). Analysis of non-linear strain-softening behaviour around tunnels. Proceedings of the Institution of Civil Engineers: Geotechnical Engineering, 168(1), 16-30. https://doi.org/10.1680/geng.13.00144

[7] Shalabi, F. I., Al-Qablan, H. A., \& Al-Hattamleh, O. H. (2009). Elasto-plastic behavior of raghadan tunnel based on RMR and hoke-Brown classifications. Geotechnical and Geological Engineering, 27(2), 237-248. https://doi.org/10.1007/s10706-008-9225-0

[8] Fahimifar, A. \& Zareifard, M. R. (2014). A new elastoplastic solution for analysis of underwater tunnels considering strain-dependent permeability. Structure and Infrastructure Engineering: Maintenance, 10(11), 14321450. https://doi.org/10.1080/15732479.2013.824489

[9] Chen, S. L. \& Abousleiman, Y. N. (2017). Wellbore stability analysis using strain hardening and/or softening plasticity 
models. International Journal of Rock Mechanics and Mining Sciences, 93(3), 260-268. https://doi.org/10.1016/j.jirmms.2017.02.007

[10] Zhang, C. G., Zhao, J. H., \& Zhang, Q. H. (2012). Convergence-confinement analysis of deep circular rock tunnels based on unified strength theory. Chinese Journal of Geotechnical Engineering, 34(1), 110-114.

[11] Pan, Y., Wang, Z. Q., \& Ren, Z. Q. (2006). Study on stress distribution of surrounding rock and work condition of tunnel based on strain nonlinear hardening and softening. Chinese Journal of Rock Mechanics and Engineering, 25(7), 1343-1351.

[12] Hou, G. Y., Li, J. J., Yang, Y., Wang, Y. X., Liang Y. H., \& Li, Q. W. (2014). Elastoplastic solution of axisymmetric circular tunnel based on power-hardening model. Rock and Soil Mechanics, 35(1), 134-142. https://doi.org/10.16285/j.rsm.2014.01.023

[13] Xiao, J. Q., Feng, X. T., Zhang, L. C., \& Qiu, S. L. (2013). Static elastoplastic analytical method of circular tunnel under uniform geostress field. Chinese Journal of Rock Mechanics and Engineering, 32(S2), 3466-3477.

[14] Alejano, L. R., Rodríguez-Dono, A., \& Veiga, M. (2012). Plastic radii and longitudinal deformation profiles of tunnels excavated in strain-softening rock masses. Tunnelling and Underground Space Technology, 30(4), 169-182. https://doi.org/10.1016/j.tust.2012.02.017

[15] Guo, Y. H., Jiang, F. X., \& Zhang, C. G. (2011). Analytical solution for critical rockburst of a circular chamber subjected to high in-situ stress. Engineering mechanics, 28(2), 118122.

[16] Su, H. J., Jing, H. W., Zhang, C. Y., \& Ma, B. (2012). Viscoelastoplastic analysis on the deep underground roadway surrounding rocks considering softening and swelling. Journal of Mining \& Safety Engineering, 29(2), 185-190.

[17] Liu, C. W. (2005). Mining disturbance and simulation of formation space stress field. Zhengzhou: Yellow River Water Conservancy Press, 124-126.

[18] Yu, M. H. (1999). Engineering strength theory. Beijing. Higher Education Press, 202-207.

[19] Xu, B. Y. \& Chen, S. C. (1981). Concise tutorial of plastic mechanics. Beijing: Tsinghua University Press, 84-87.

[20] Cai, M. F., He, M. C., \& Liu, D. Y. (2002). Rock mechanics and engineering. Beijing: Science Press, 320-323.

[21] Zhu, C. Q., Yin Z. Q., Li C. M., \& Feng R. M. (2016) Elastoplastic Analysis of Tunnel Surrounding Rocks based on the Statistical Damage Constitutive Model. Journal of Engineering Science and Technology Review, 9(3), 27-34. https://doi.org/10.25103/jestr.092.05

\section{Contact information:}

Chuanqi ZHU, PhD

(Corresponding author)

State Key Laboratory of Mining Response and Disaster Prevention and Control in Deep Coal Mines, Anhui University of Science and Technology,

No.168, Taifeng Road, Huainancity, Anhui Province, China, 232001

E-mail: zhuchuanqi2013@126.com

Xingang NIU, MS

State Key Laboratory of the Gas Disaster Detecting, Preventing and Emergency Controlling

No. 55, Shangqiao No. 3 Village, Shapingba District, Chongqing, China, 400044 E-mail: xingangniu@163.com

Huaifu LIU, MS

State Key Laboratory of the Gas Disaster Detecting, Preventing and Emergency Controlling,

No. 55, Shangqiao No. 3 Village, Shapingba District, Chongqing, China, 400044 E-mail: 15395412690@163.com

Haifeng MA, PhD

School of Mining and Safety Engineering, Anhui University of Science and Technology,

No.168, Taifeng Road, Huainancity, Anhui Province, China, 232001

E-mail: haifeng990@163.com

Zhenhua JIAO, PhD

State Key Laboratory of Mining Response and Disaster Prevention and Control in Deep Coal Mines, Anhui University of Science and Technology,

No.168, Taifeng Road, Huainancity, Anhui Province, China, 23200

E-mail: jiaozhenhua-888@163.com 